\title{
Algorithm for calculation of channel deformation in soils of various graininess
}

\author{
Anna Hodzinskaya* \\ Moscow State University of Civil Engineering, Yaroslavskoe shosse, 26, Moscow, 129337, Russia
}

\begin{abstract}
The article deals with deformations of channel beds in of various-grained, non-cohesive, rather coarse-grained soils having more than $0.55 \mathrm{~mm}$ mean diameter of particles that might form natural pavement at velocities slightly higher than non-erosive ones. Laboratory experiments prove that as soon as natural pavement has formed, modelled bed deforms only a little. Is proposed scheme of calculation of parameters of the channel and the channels deformation. The bed should be erosion normally of the slopes. To estimate the time of deformation is proposed to use for the flow of the bottom sediments of probabilistic formulas, based on a model of K. I. Rossinskii. To determine the diameter of armoring and depth of erosion of the riverbed of the proposed new method of calculation that gives the values close and experienced and method of A.V. Magomedova. Is given block diagram of the calculation riverbed in a nonuniform particle size. Channels sizes you can define by setting a slight excess permissible velocities, or you can take specified values. There is good agreement between the values of erosion obtained in the experiments and in the calculations. In the presence of the surface layer of the slope or the ballast layer of geotextile of various-grained of a certain thickness may be formed armoring, capable of protecting the slopes of the channel from erosion.
\end{abstract}

\section{Introduction}

Construction of soil channels without concrete reinforcement keeps is still appropriate because of its economic attractiveness. High velocities possible in concrete bed are not required in most cases, as the surface has a slight slope. Problems of filtration and overgrowing can have alternative solutions, e.g. with the use of geomembranes [1] and/or other methods.

Initial data for hydraulic calculation of the channel in a non-cohesive soil by method of permissible speed are: a design discharge, a curve of soil granulometry and its weighted mean diameter, a coefficient of roughness. The calculation begins with allocating or finding the maximum depth.

As a rule, cross-section profile is prescribed to be parabolic or trapezoid. Obtaining the maximum depth of bed by formulas for parabolic channel, later, going to medium depth

\footnotetext{
* Corresponding author: khodzinskaya2010@yandex.ru
} 
and, at last, to the width at the top. Defining the maximum depth of a channel according to the formulas for a parabolic channel, you go to the average depth, then the width of the top.

If we consider the squares of parabolic and trapezoidal bed to be equal, we arrive to the depth of the trapezoidal channel:

$$
h=\frac{2 \omega}{B+\sqrt{B^{2}-\frac{4 \omega}{\operatorname{tg} \alpha}}},
$$

where $\alpha$ means a slope steepness angle.

To find a non-erosive velocity, recommends allowing for non-uniform distribution of velocity among the channel section, i.e. lower stability for slopes wash-out and, as a result, lower non-erosive velocity.

This, with slope steepness angle $\alpha$ taken as a half of angle of internal friction $\varphi$, the coefficient that accounts for lower stability of the particles at the slope, is

$$
\psi^{2}=\cos \alpha \sqrt{1-\operatorname{tg}^{2} \alpha / \operatorname{tg}^{2} \varphi} \text {. }
$$

Deformations of soil-bed channels has been studied for a long time; the results of experiments are set out in works [ 2,3,4] that deal with deformation of channels having beds formed of rather fine or homogenous non-cohesive soils that can sustain velocities equal or slightly different to non-erosive ones. Certain vagueness is explained by the fact that only some authors give details of non-erosive velocity obtaining (by experiment or by formulas).

The experiments deformed the beds as follows: first, ridges were formed at slopes and then at the bottom; this was followed by widening of the bed and reducing of depth. In continuous experiments $[2,4]$ bed deformations developed point bars. In such beds, dynamical axis of a water-course curves in plan. That generally similar processes take place in full-scale channels, is proved by numerous literature sources, e.g. [5].

Beds formed by coarse-grained soils, various-grained are deformed differently, as they form natural pavement that hinders deformations.

Natural pavement (i.e. a layer of large particles that accumulates during bed wash-out when smaller particles are removed by water), according to studies $[6,7,8,9,10,11]$ only forms in various-grained, non-cohesive soils (coefficient of heterogeneity $K_{h}=d_{\text {mean }} / d_{95}<$ 0.8 ) and in rather coarse non-cohesive soil [ 7 ] having grains of more than $0.55 \mathrm{~mm}$ in diameter. This is because, as [8] shows, when particles smaller than 0.5-0.6 mm lose their stability, they convert to suspension almost instantly after beginning of motion.

Natural pavement in river beds has potent effect on the river morphology by reducing general wash-out, and projecting of channels in various-grained, non-cohesive soils has certain features.

Natural pavement forms by falling and accumulating of large particles in the bottom of the ridges. Finer particles form active layer of the soil and move ridge-shaped along the layer of bottom, gradually increasing particles. Numerical methods $[9,10,11,15]$ described process of coarsening the particles in the surface layer.

Some laboratory experiments refined the process of general wash-out of the bed in various-grained, non-cohesive soils and regularities of initial soil re-sorting.

\section{Methods}

Laboratory research of deformation of bed formed by in heterogenous in sizes, noncohesive soil was made at $18 \times 2 \times 1 \mathrm{~m}$ hydraulic flume of variable slope. Three types of heterogenous in sizes, non-cohesive soils having mean weighted diameter of $0.50 \mathrm{~mm}$ were involved in experiments I, II, and III) ; $1.38 \mathrm{~mm}$ in experiment IV and $0.64 \mathrm{~mm}$ in experiment V. Coefficients of soil heterogeneity $\left(K_{h}=d_{m} / d_{95}\right.$, where $d_{m}$ is mean-weighted 
diameter of soil, - diameter of particles; $95 \%$ of soil weight is made of particles of smaller size) made, respectively, $0.27,0.29$, and 0.32 , i.e. the soil was heterogenous in all cases.

Experiments were preceded with soaking of soil, forming of trapezoidal bed and experimental obtaining of non-erosive velocities. Parameters of experiments are shown in Table 1, where all the values of water-course hydraulic parameters are given for the moment of time before the experiment.

In experiments I and III deformations were the same as in homogenous soils [3,5,6], but experiment III saw less deformations. Ridges originated at the bottoms of the slopes, then propagated along all the bed and got warped. The bank collapsed where the bottom of the warped ridge adjoined it. Experiment II showed almost no deformations.

Table1. Main parameters of experiments

\begin{tabular}{|l|l|l|l|l|l||l|l|l|}
\hline Experiment & $\begin{array}{l}Q, \\
l / s\end{array}$ & $\begin{array}{l}h_{\text {mean }}, \\
s m\end{array}$ & $\begin{array}{l}h_{\max }, \\
s m\end{array}$ & $\begin{array}{l}B, \\
s m\end{array}$ & $\begin{array}{l}I \\
X 10^{3}\end{array}$ & $\begin{array}{l}U_{\text {mean, }} \\
s m / s\end{array}$ & $B / h_{\text {mean }}$ & $m$ \\
\hline I & 40.5 & 9.3 & 13.8 & 119 & 1.2 & 36.6 & 12.7 & 2.5 \\
II & 35.5 & 9.9 & 14.6 & 141 & 0.55 & 26.0 & 14.2 & 3.1 \\
III & 35.5 & 8.2 & 12.8 & 127 & 0.8 & 33.4 & 15.3 & 3.1 \\
IV & 42 & 8.0 & 12.2 & 130 & 0.95 & 38.8 & 16.1 & 3.2 \\
V & 45.5 & 9.0 & 13.9 & 134 & 1.0 & 37.8 & 14.9 & 3.2 \\
\hline
\end{tabular}

Here: $Q$ - flow of water, $h_{\text {mean }}$ and $h_{\text {max }}$ - mean and maximum depth, $I$ - bias, $U_{\text {mean }}$ mean velocity, $m=\operatorname{ctg} \alpha$ - coefficient of laying the slope.

Experiments IV and V significantly changed the type of bed deformations. In their beginning, ridges of the so called deficiency forms formed by small fraction sand appear first at the slopes and then at the bottom. With time, they become lower and more shallow to degenerate into narrow strips of fine sand first at the slopes and then at the bottom and form a layer of larger particles, or natural pavement. The bed got wider, but just slightly. Soil composition of slopes changed significantly, as large particles were accumulating at the bottoms of ridges. Smaller particles were washed out from the slopes and gathered in ridges trailed along the layer of large particles at the bottom and were gradually carried away with the water-course.

Findings of soil granulometric analysis, obtained by experiments, are shown in the Table 2. It should be noted that the process of particles increasing was faster in the experiment IV, than in the experiment $\mathrm{V}$, because the former used more particles of larger size. The largest particles of soil lay in the bottom parts of slopes where the wash-out is the greatest

Table 2. Characteristics of soil for various points of cross section in experiments III-V

\begin{tabular}{|l||l|l|l||l|l|l|l|l|l|l|l|l|}
\hline $\begin{array}{l}\text { Experiment } \\
\text { No. }\end{array}$ & \multicolumn{2}{|l|}{$\begin{array}{l}\text { At the water } \\
\text { edge }\end{array}$} & $\begin{array}{l}\text { In the } \\
\text { middle of } \\
\text { the slope }\end{array}$ & $\begin{array}{l}\text { At the } \\
\text { bottom of } \\
\text { the slope }\end{array}$ & $\begin{array}{l}\text { At the } \\
\text { bottom of } \\
\text { ridges }\end{array}$ & $\begin{array}{l}\text { At the top } \\
\text { of ridges }\end{array}$ \\
\cline { 2 - 12 } & $\begin{array}{l}d, \\
\mathrm{~mm}\end{array}$ & $K_{h}$ & $\begin{array}{l}d, \\
\mathrm{~mm}\end{array}$ & $K_{h}$ & $\begin{array}{l}d, \\
\mathrm{~mm}\end{array}$ & $K_{h}$ & $\begin{array}{l}d, \\
\mathrm{~mm}\end{array}$ & $K_{h}$ & $\begin{array}{l}d, \\
\mathrm{~mm}\end{array}$ & $K_{h}$ \\
\hline III & 0.50 & 0.27 & 0.56 & 0.31 & 1.50 & 0.26 & 0.73 & 0.32 & 0.21 & 0.42 \\
\hline IV & 1.32 & 0.25 & 1.97 & 0.31 & 2.50 & 0.39 & 1.20 & 0.32 & 0.32 & 0.64 \\
\hline $\mathrm{V}$ & 0.68 & 0.25 & 1.21 & 0.31 & 2.30 & 0.34 & 1.11 & 0.34 & 0.28 & 0.60 \\
\hline
\end{tabular}

Calculation of bed reorganization may employ the procedure offered in [7], where layer-by-layer wash-out occurred in perpendicular to the slopes, that agrees with the results of experiments. In experiments IV and V (before consumption increase) bed widened not 
more than by $3 \%$, in calculations the value was $12 \%$. Diameter of natural pavement particles that formed as a result of experiments differed not more than $21 \%$ from the one calculated.

Fig. 1 shows changing of the bed relative width $\left(\mathrm{B} / \mathrm{h}_{\text {mean }}\right.$ - the width along the edge to the mean depth) in time in experiments made by the author and in experiments made in homogenous soil without forming of natural pavement.

$\mathrm{B} / \mathbf{h}_{\text {mean }}$

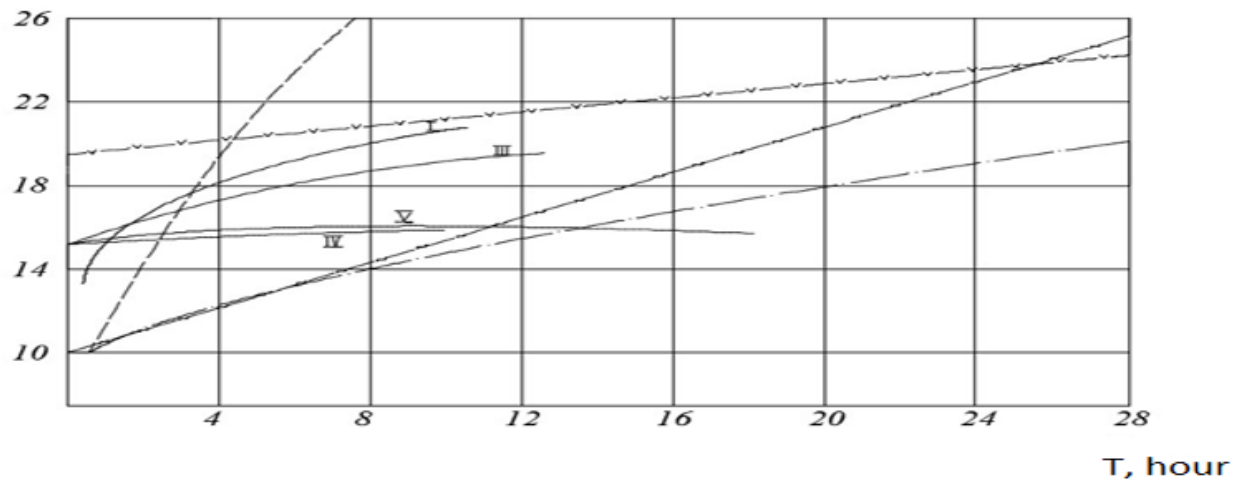

Fig.1. Changing the relative width of channels in time: - author $--[3]-\sim 2]-v-v-[4]$

In procedure [6], the most dubious is the issue of finding the non-erosive velocity during forming of natural pavement, because the formula for non-erosive velocity includes a diameter that defines the height of roughness protrusions $\left(\mathrm{d}_{95}\right)$ and a diameter of particles for which non-erosive velocity is to be obtained.

Diameter of natural pavement at $\mathrm{j}$-th step is obtained from the formula:

$$
D_{n p j}=D_{n p j-1}+\sum_{j=k}^{j} \Delta n_{j-1} P_{l j}\left(1-\frac{d m}{d l j}\right)
$$

where $d_{l j}$ and $P_{l j}$, respectively, are mean diameter and relative weighted content of large fractions in initial soil; these fractions accumulate in bed under hydraulic conditions that correspond to $\mathrm{j}$-th step of calculation, $\Delta n_{\mathrm{j}}$ mean interval of wash-out value that goes normally to the slope.

It should be pointed out that in experiments described natural pavement formed with $K_{h}$ $=0.29-0.32$ coefficients of heterogeneity and only in experiments where mean weighted diameter of particles was more than $0.5 \mathrm{~mm}$.

This means that values of coefficients of heterogeneity are still insufficient for forming natural pavement.

It follows from experiments described that $d_{m}=0.55 \mathrm{~mm}$ can be taken as a rough boundary value of particles size that allows forming of natural pavement.

\section{Results and Discussion}

In accordance with [16] heterogeneity in size of fine-grained soils (with mean diameter of particles less than $0.55-1.0$ can well be omitted during wash-out.

For $0.8 \mathrm{~mm}$ diameter of particles, Van Rijn showed changing of critical velocity [17], as per [6 ], it changes with particles diameter $d<1 \mathrm{~mm}$. Studies [18] and [19] show that with mean size of soil particles being $0.33-0.65 \mathrm{~mm}$, the Shields [20] graph shows changes in dependence for stability coefficient of various-grained, non-cohesive soils. For more coarse-grained soils (larger than $0.33-0.65 \mathrm{~mm}$ ) it passes lower than for homogenous in 
size, and for finer-grained soils, on the other hand, it passes higher. Most likely, it is explained by changing of method for stability loss of particles finer than $0.5 \mathrm{~mm}$ : probability of their suspension is higher, than probability of turnover or beginning of slipping [8].

We see natural pavement as such coarsening of surface layer of particles, that, when reached, does not cause any further deformations of bed. The composition of the natural pavement that forms at the surface of the soil depends on the depth of wash-out, i.e. the depth of soil conversion layer. The wash-out stops when diameter of particles in the natural pavement exceeds the diameter of soil grains resistive to wash-out under current hydraulic conditions in the flow.

To find diameter of particles resistive to wash-out under current hydraulic condition we account for shading effect of larger particles [7] and, for relation $\mathrm{d}_{\mathrm{I}} / \mathrm{d}_{\mathrm{r}}>0.4$ we accept the following expression for bottom non-erosive velocity in various-grained noncohesive soils:

$$
U_{\Delta n}^{h}=\frac{U_{\Delta n} \psi}{\left(d_{i} / d_{r}\right)^{0,157}}
$$

where $d_{i}$ and $d_{\mathrm{r}}$ mean diameters of particles in $i$-th fraction and the particles that define the roughness of the bed ( $d_{95}$ in the beginning of calculation and $D_{\mathrm{np}}$ for further steps).

Bottom velocity at the height of roughness protrusions:

$$
\bar{U}_{\Delta}=\frac{1,16 U d_{r}^{0,2}}{h^{0,2}}
$$

where $U$ means an average velocity at the vertical of depth $h$.

Minimum diameter of fractions is obtained for each step of calculation from the formula:

$$
d_{c r . \min }=\left(\frac{1,16 U_{m} d_{r}^{0,043}}{h^{0,2} \psi} \sqrt{\frac{\rho n_{1}}{7,81 m_{1}\left(g\left(\rho_{s}-\rho\right)\right.}}\right)^{2,915}
$$

Reasoning that the largest diameter of moving soil particles makes $d_{\text {cr.min }}$ affords identifying the moving fractions of the particles.

Estimation of bed deformations time requires calculation of bed-load consumption per each step of calculation. Total firm consumption, expressed as the sum of moving fractions consumption, is found for each fraction of the moving soil:

$$
\bar{G}=\sum_{i=1}^{n} G_{i}
$$

After correction of dependence for mean relative height of particles jumps in nearbottom area [22]:

$$
\frac{\bar{H}}{d}=0,63\left(6,25-\frac{W}{U_{*}}\right)\left(\frac{W}{U_{*}}\right)^{-0,5},
$$

where $\bar{H}$ is a mean height of jumps; $d$ is a mean diameter of particles, $W$ means hydraulic size of particles;,$U_{*-}$ means dynamic velocity of the flow; now, we can correct the formula given in $[23,24]$, for specific volume consumption of bed-load:

$$
G_{i}=0,69\left(\varphi_{i}-\varphi_{s i}\right)\left(6,25-\frac{W}{U_{*}}\right)\left(\frac{W}{U_{*}}\right)^{-0,5} U_{*} d,
$$

where $\varphi_{i}$ and $\varphi_{s i}$ are, respectively, probability of tearing off the bottom and suspension of particle in $i$-th fraction.

A.V. Magomedova i (3) deducted the dependence with some assumptions; in particular, it is obtained from the premise that granulometry of soil is described by normallylogarithmic and gamma distribution.

To check universality of the dependence (3), we, like in [6] adhere to layer-by-layer wash-out and accumulation of coarse fraction in each step to find diameter of pavement for 
particles not moved by the fractions flow with known mean velocity in the flow. Unlike of dependence offered in [6], roughness is defined not by permanent diameter $d_{95}$, and, since the second step of calculation, by the diameter of natural pavement forming - $D_{\mathrm{np}}$.

Let's find the diameter of natural pavement from the granulometry of particular soil and its porosity. Like in $[6,19]$ we will follow layer-by-layer wash-out pattern and find the amount of coarse particles remaining at the bottom, for each step of the preset wash-out interval. Diameter of natural pavement is expressed as a weighted mean square value.

In case value obtained from formula (11) will be less than diameter of maximum coarse particles, the natural pavement may form, if it will be more, the calculation stops.

Ordinate of integral granulometry curve $P_{1 . \mathrm{d} 1}$, that corresponds to the value, can be found by interpolation between values of coarse-fraction diameters - $d_{1 . \mathrm{d} 1}$.

Find the percentage of coarse particles in the soil:

$$
P_{\text {cr.d1 }}=1-P_{\mathrm{d} 1}
$$

Value $P_{1 . \mathrm{d}}$ finds diameter of coarse particles that are not moved by the flow and form natural pavement $-d_{1 . i}$. To make interpolation convenient, it is advisable to compile an additional table of values $P_{l . i}$ at $d_{l . i}$ or plot an appropriate graph by adding the upper boundary value for the coarsest fraction.

With preset wash-out depth $\Delta h_{l}$, the first step of calculation finds the volume of the soil washed out:

$$
W_{\mathrm{e} .1}=\Delta h_{1}(1 x 1)
$$

where $1 \times 1\left(\mathrm{~m}^{2}\right)$ means a square of the site being washed out.

The volume occupied by soil particles in volume $W_{\mathrm{e} .1}$ :

$$
W_{\mathrm{s} .1}=(1-p) W_{\mathrm{e} .1}
$$

where $p$ means a porosity of soil, we accept that porosity in volume is the same as porosity in square (for coarse-grained sand and gravel-pebble soils $p=0.28-0.40$ ).

The volume of large(coarse) particles in volume $W_{\mathrm{e} 1}$ :

$$
W_{l . s 1 .}=P_{l . \mathrm{d} .1 .} W_{\mathrm{s} 1}
$$

Find volume and square of midsection for the large (coarse) particle of diameter $d_{l . \mathrm{d} 1 \text {. }}$ $W_{l}$ and $S_{l}$. The amount of coarse particles in the amount of soil being washed out $W_{\mathrm{e} .1}$ :

$$
n_{l .1}=\frac{W_{l . s 1}}{W_{1}}
$$

The relation square occupied by large(coarse) particles:

$$
S_{l .1}=n_{l .1} S_{1} /(1 \times 1)
$$

Diameter of natural pavement at the first step of calculation is defined as mean weighted in square on the

basis that coarse particles of diameter $d_{l . \mathrm{dl}}$ occupy square of $S_{l .1} \quad$, and all other particles have mean weighed mean diameter $d_{m}$ and occupy remaining square:

$$
D_{n . p .1}=d_{m}\left(1-S_{l .1}\right)+d_{l . d 1} S_{l .1}
$$

In the next calculation step, with wash-out interval $\Delta h_{i+l}$ preset, minimum diameter of particles not moved will reduce because of lower average velocity, and percentage of coarse particles involved in forming the natural pavement will increase. To obtain the square occupied by coarse particles, the second step of calculation employs adding the square occupied by coarse particles and obtained in the first step with the square obtained in the next (second) step of wash-out, $S_{c 2}$,

Diameter of natural pavement in $\mathrm{j}$-th step is:

$$
D_{n p . j}=d_{m}\left(1-\sum_{j=1}^{n} S_{l . j}\right)+\sum_{j=1}^{n} d_{l . j} S_{l . j}
$$


The second step of calculation involves three components:

$$
D_{n . p .2}=d_{l . d 1} S_{l .1}+d_{l . d 2} S_{l .2}+d_{m}\left(1-S_{l .1}-S_{l .2}\right)
$$

etc.

Wash-out and forming of natural pavement will stop when $d_{\text {cr.min }}$ will exceed the value of maximum size of the particles.

Correlation of calculations by the method offered, experimental result and by the method [6] showed the divergence of not more than $10 \%$, that proves the sufficient universality of formula (3) and potentials for use of this method.

Based on the described procedure of calculation of the deformation of riverbed in a nonuniform particle size incoherent (various-grained) soils of the proposed algorithm. A detailed block diagram shown in Fig .2 . Channel settings you can define by the formulas (1) and (2 ) setting a slight excess permissible velocities, or you can take specified. Table 3 shows the comparing the experimental and calculated values of parameters.

Table 3. Experienced and design. values of parameters

\begin{tabular}{|l|l|l|l|l|l|l|l|l|l|l|}
\hline \multirow{2}{*}{ Experiment } & \multicolumn{3}{|c|}{$B, \mathrm{~m}$} & \multicolumn{2}{|c|}{$B / h_{\text {mean }}$} & \multicolumn{2}{c|}{$U_{\text {mean }} \mathrm{m} / \mathrm{s}$} & \multicolumn{2}{l|}{$d 10^{-3}, \mathrm{~m}$} \\
\cline { 2 - 13 } & & initial & finite & initial & finite & Initial & finite & initial & finite \\
\hline III & experienced & 1.27 & 1.45 & 15.1 & 19.4 & 0.336 & 0.326 & 0.50 & 1.50 \\
\hline III & design & 1.27 & 1.34 & 15.3 & 16.0 & 0.334 & 0.317 & 0.50 & 1.52 \\
\hline IV & experienced & 1.30 & 1.34 & 16.1 & 17.1 & 0.378 & 0.336 & 1.38 & 2.76 \\
\hline IV & design & 1.30 & 1.38 & 16.1 & 16.9 & 0.376 & 0.372 & 1.38 & 2.66 \\
\hline V & experienced & 1.34 & 1.40 & 14.9 & 15.3 & 0.378 & 0.336 & 0.64 & 2.65 \\
\hline V & design & 1.34 & 1.40 & 14.9 & 15.3 & 0.378 & 0.353 & 0.64 & 2.00 \\
\hline
\end{tabular}

Work [25] approached consideration of natural pavement for projecting of channels in heterogenous in sizes, non-cohesive soils occurring widely in Lithuania. It is noted that the pavement layer does not break when exposed to the flow with velocity greater than the velocity at which the natural pavement was forming. In places of slope change special depressions should be made to accumulate fine particles washed out.

To protect the geomembrane [1]., it is proposed to cover the layer of sorted crushed stone or gravel to a depth of $1 \mathrm{~m}$. the same effect can be achieved if you leave a protective layer the entire depth of the sand and the upper part of the slope covered with a layer of variousgrained sand, estimated thickness, which is formed smoothmode, but much cheaper, as the cost of gravel (broken granite) is, on average, 2.5 times more than the one of the construction sand. 


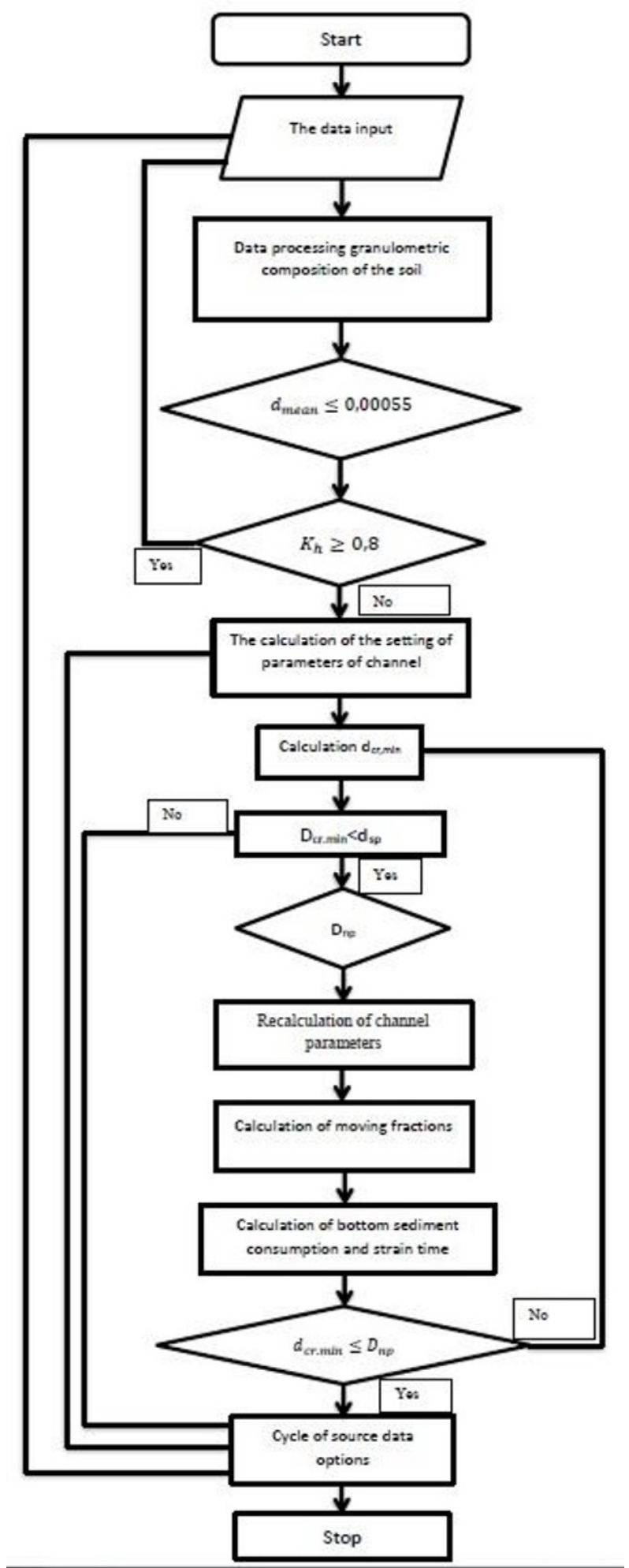

Fig.2. Block diagram of algorithm of calculation. 


\section{Conclusions}

1. While forming natural pavement, beds in heterogenous in sizes, rather coarse-grained sand soils deform not like in homogenous sands that must be considered in calculations.

2. Diameter of natural pavement and depth of bed wash-out are found by the new method of calculation that gives the values close experienced and method of $\mathrm{A}$. V. Magomedova.

3. Verification of some aspects of washing-out in heterogenous in sizes, non-cohesive soils require experimental studies for wide range of initial parameters of soils.

4. The device mounting the surface layer of the slope or the ballast layer of geotextile heterogeneous various-grained soil with a certain thickness, can protect the slopes of the channel from erosion.

\section{References}

1. Rekomendacii po proektirovaniyu I stroitel'stvu protivofil'tracionnyh ustroistv iz geomembrany dlja gidrotehnicheskih sooruzhenii v uslovijah respubliki Kazahstan.

[Recommendations for the design and construction of devices of impervious geomembranes for hydraulic structures in the Republic of Kazakhstan.] TOO KazGeoSintetika Astana: 2011, 48 p. .(rus.)

2. Sharashkina N.S. Rol' grjadoobraznogo dvizhenija nanosov v formirovanii rechnyh ruse [The role graduarse the movement of river load in the formation of river channels ] Izvestija AN SSSR, OTN,1959. Pp. 212-223. .(rus.)

3. Mihailova N.A. Shevchenko O.B., Seljametov M.M. Issledovanija formirovanija ustoichivyh rusel kanalov studies of formation of stable channels channels [Studies of formation of stable channels channels ] Gidrotehnicheskoe stroitel'stvo, 1980.Pp.40-46. (rus.)

4. Troickii V.P., Laksberg A.I., Agaev A.Ja. Rezul'taty yeksperimental'nyh issledovanii na laboratornyh peschanyh kanalah. [Results of experimental studies on laboratory sand channels]// Proc. // Sb. «Gidravlicheskie issledovanija v vodnom hozjaistve» [Hydraulic research in the water sector ]M., V/O Soyuzvodproekt, M.: 1982,Pp. 89-99. .(rus.)

5. Kosichenko, YU. M. Kanaly perebroski stoka Rossii. [Channels of redistribution of Russia] - Novocherkassk: NGMA, 2004, 470 p. .(rus.)

6. Rekomendacii po raschetu obshego razmyva rusl, slozhennyh svjaznymi i nesvjaznymi gruntami pri proektirovanii transportnyh gidrotehnicheskih sooruzhenii [Guidelines for calculation of total erosion of riverbeds composed of cohesive and cohesionless soils the design of transport hydraulic structures ]/ M.:CNIIS.-1981, 90p .(rus.)

7. Khodzinskaya A.G. Uchet neodnorodnosti nesvjaznogo grunta, slagayushego ruslo pri raschete ego razmyva. [Registration of inhomogeneous cohesionless soils, forms a channel for the calculation of its erosion ]// Izvestija vuzov. Stroitel'stvo, 2004. Vol.9. Pp. 61-65. (rus.)

8. Khodzinskaja A.G. Granicy grjadovoi formy dvizhenija nanosov. [The Border of the movement in the form of ridges sediment ]/ Vestnik MGSU, 2015., No.9, Pp.122129.(rus.)

9. Jia B, D. Zhong D. Scouring and Armoring in Alluvial Rivers ICHE 2014 Bundesanstalt fur Wasserbau, Hamburg, (ISBN 978-3-939 230-32-8), 2014. Pp. 583590.

10. Zhong Deyu, Zhang Hongwu, Wang Guangqian, Basic equation for variation of bed material composition in active layer of alluvial river. Journal of Hydraulic Engineering. 2004,9 :Pp. 24-31 . 
11. Zhong Deyu, Wang Guangqian, Ding Yun. Simulation of bed load graing in alluvial rivers with sand bed. Advance in water science. 2007, 18(2). Pp. 23-30.

12. Liu Jinmei, Wang Shiqiang, Wang Guangqian, Effect of Coarsening Surface Bed Material on Non-Equilibrium sediment transport Process during river degradation[J]. Journal of Hydraulic Engineering, 2002(2): Pp. 47-53.

13. Visconti, F., Stefanon, L., Camporeale, C., Susin, F., Ridolfi, L., Lanzoni, S. Bed evolution measurement with flowing water in morphodynamics experiments. Earth Surf. Process. Landf. 2012 , 37 ,Pp. 818-827.

14. Török, G.T.; Baranya, S.; Rüther, N.; Spiller, S. Laboratory analysis of armor layer development in a local scour around a groin. In Proceedings of the International Conference on Fluvial Hydraulics River Flow, Lausanne EPFL, Lausanne, Switzerland, 3-5 September 2014.

15. NO.Török, G.T.; Baranya, S.; Rüther, N. Three-dimensional numerical modeling of non-uniform sediment transport and bed armoring process. In Proceedings of the 18th Congress of the Asia \& Pacific Division of the IAHR 2012, Jeju, Korea, 19-23 August 2012; P. 816.

16. Mazhidov T.SH. Yeksperimental'nye issledovanija vlijanija sostava nanosov na harakteristiki potoka i rusla . [Experimental study of the influence of sediment composition on the characteristics of flow and bed ]/ Trudy V Vsesoyuznogo gidrologicheskogo s"ezda, t.10, kn.2, L.: Gidrometeoizdat, 1988, Pp.40-47. .(rus.)

17. Rijn van L.L. Sediment transport. Part I: Bed-load transport,// J.Hydraul. Eng., 1984, 110 , No. 10.

18. Knoroz V.S. Nerazmyvayushaja skorost' dlja nesvjaznyh gruntov i faktory ee opredeljayushie.- [Nerazmennaya speed for non cohesive soils and the factors determining it.] Izvestija VNIIG im. B.E.Vedeneeva.,1959, t.69,Pp. 62-81. .(rus.)

19. Kantarzhi I.G., Rogachko S.I., Vaitman V.V. Volnovaja pererabotka poperechnogo pljazhnogo otkosa, slozhennogo neodnorodnym materialom [Processing transverse Wave beach slope, composed of heterogeneous material ] // Gidrotehnicheskoe stroitel'stvo, №2, 2007, Pp..23-29. (rus.)

20. Schields A. Anwendung der Aechnlichkeitsmechanik und der Turbulenzforschung auf die Geschiebebewegung. Mitteilungen d. Preuss. Versuchanstalt. f. Wasserbau u. Schiffbau. Berlin, 1936.H. 26.

21. Wu, W.; Wang, S.S.Y.; Jia, Y Parker, G. Transport of Gravel and Sediment Mixtures. In Sedimentation Engineering: Processes, Measurements, Modeling, and Practice; García, M., Ed.; ASCE: Reston, VA, USA, 2008. Pp. 165-251.

22. Khodzinskaja A.G., Zommer T.V. Vysota podnjatija chastic donnyh i vzveshennyh nanosov . [Raising the height of the particles of bottom and suspended sediments] // Vestnik MGSU, No.11, 2014.Pp.161-170. .(rus.)

23. Verbickii V.S., Khodzinskaja A.G. Opredelenie rashoda donnyh nanosov s pomosh'yu harakteristik sal'tacii [Determination of the flow rate of bottom sediment with characteristics of saltation] // Gidrotehnicheskoe stroitel'stvo, 1999, No. 6 Pp. 24-30. (rus.)

24. Khodzinskaya A.G., Verbitsky V.S. Characteristics of saltation and expression for bedload transport. Proc. of the 10 ISRS, Vol. III, M., MGU, Pp. 168-175. (rus.)

25. Zhdankus N. Razmyv i samootmostka nesvjaznogo neodnorodnogo grunta.[ Erosion and smoothmode heterogeneous incoherent soil] / /Sb. Dvizhenie nanosov v otkrytyh ruslah \{The movement of sediment in open channels ], M: «Nauka, 1970 Pp. 228-231. (rus.) 